\title{
Gênero cordel: uma sequência didática como "troféu"
}

\author{
Ladmires Luiz Gomes de Carvalho (SEECRN)* \\ https://orcid.org/0000-0001-6890-4338 \\ Andréa Jane da Silva (UERN)** \\ https://orcid.org/0000-0002-8760-3845 \\ Maria Fabiana Medeiros de Holanda (UFRN)*** \\ https://orcid.org/0000-0001-7694-4874
}

\begin{abstract}
Resumo:
A necessidade de se trabalhar a escrita em sala de aula tomando como base os diversos gêneros textuais coloca os professores diante da decisão de qual gênero levar para suas aulas de Língua Portuguesa. Assim sendo, pensando no aspecto da relevância cultural do cordel para o Nordeste, decidimos empreender um estudo sobre esse gênero. Nosso objetivo neste artigo é fazer um recorte de um estudo mais amplo com vistas a apresentar a análise de um trabalho com uma Sequência Didática. Dessa forma, apresentamos as etapas dessa sequência didática realizada numa turma de 9o ano de uma escola pública de Natal. Os resultados da análise nos mostram que se trata de um gênero fecundo para se trabalhar em nosso contexto, uma vez que instiga e motiva os alunos em seus processos de leitura e de escrita, promovendo o desenvolvimento dessas habilidades.
\end{abstract}

Palavras-chave: Ensino de leitura e de escrita; Literatura de cordel; Sequência didática.

\section{Abstract:}

\section{Cordel literature: a didactic sequence as a "prize"}

The necessity of dealing with different textual genres when practicing writing takes teachers to face the crucial decision of which genre to take to their Portuguese classes. Therefore, because of the cultural relevance of the cordel literature to the Northeast of Brazil, we have decided to undertake a study

\footnotetext{
Professor de Língua Portuguesa na Educação Básica (Ensino Fundamental e Médio). Mestrado em Letras pelo PROGRAMA DE PÓS-GRADUAÇÃO EM LETRAS - PROFLETRAS NATAL/RN. Lattles: http://lattes. cnpq.br/2255741993647606.E-mail: ladmires@hotmail.com

** Mestre em Letras pelo PPGEL/UFRN e doutora em Educação pela UFRN. Professora Adjunta IV da Universidade do Estado do Rio Grande do Norte. Lattles: http://lattes.cnpq.br/3449646815267434. E-mail: ajanesilva@hotmail.com

*** Mestre em Linguística Aplicada pelo Programa de Pós-Graduação em Estudos da Linguagem. Professora substituta da Universidade Federal do Rio Grande do Norte, departamento de Letras/CERES/DLC. Lattles: http://lattes.cnpq.br/2859229443915296.E-mail: hmfabiana@hotmail.com
} 
on this textual genre. Our aim in this paper is to focus on one aspect of a broader research in order to presente the analysis of a Didactic Sequence produced on cordel. Thus, it is presented the stafes of this sequence carried out in a 9th grade class at a public school in Natal/RN. The result of the analysis show us that it is a fertile genre to work in out contexto since it instigates and motivates students on their Reading and writing processes, promoting the development of these language skills.

Keywords: Reading and writing; Cordel literature; Didactic sequence.

\section{Introdução}

0 trabalho com a leitura e a escrita deve ser uma constante no fazer pedagógico do professor de Língua Portuguesa da educação básica. Nesse sentido, cabe, sobremaneira, ao professor dessa área oportunizar aos alunos um contato com os gêneros discursivos literários que fazem parte tanto do universo canônico quanto daquele considerado marginal. Por essa razão, é que propomos esta pesquisa, que tem como objeto de estudo o gênero discursivo cordel. Neste artigo, fazemos um recorte de uma pesquisa mais ampla realizada durante o Programa de Mestrado Profissional em Letras. A questão central que norteou a nossa pesquisa foi a seguinte: como o trabalho com o gênero cordel pode auxiliar no processo de desenvolvimento da habilidade de escrita de alunos do 90 ano?

0 objetivo nesse recorte será apresentar a sequência didática elaborada tomando como base o gênero cordel e algumas reflexões decorrentes desse trabalho realizado. A pesquisa foi desenvolvida com os alunos do 9o ano "A", do turno vespertino, do Ensino Fundamental, da Escola Estadual Professor José Fernandes Machado, localizada em Natal/RN, e buscou investigar como a utilização do gênero discursivo cordel, estudado sob o enfoque de uma Sequência Didática $\mathrm{SD}$, influenciou o processo de autoria desses sujeitos dentro e fora da esfera escolar.

\section{Sequência didática com gênero cordel: análise numa turma de 9o ano}

Partindo do princípio de que não há docência sem discência (FREIRE, 2006), é imprescindível que o professor tenha em mente alguns saberes indispensáveis ao elaborar uma Sequência Didática, resgatando os conhecimentos que os alunos já têm internalizados. Além disso, é necessário compreender, como nos lembra Antunes (2009), que o professor precisa estar munido de um arsenal teórico pautado em princípios objetivos e sólidos. Desse modo, torna-se possível o desenvolvimento de uma prática eficiente, próxima daquilo que buscamos como ideal para o ensino de língua portuguesa. Essa proximidade com o ideal seria a aplicação de uma SD que discutisse o fenômeno da linguagem, não como um construto isolado, mas numa perspectiva produtiva, centrada nos gêneros discursivos por meio dos quais os sujeitos se posicionam, falando para alguém seja pela oralidade seja pela escrita. Considerando, então, as reflexões sobre a concepção de linguagem numa perspectiva bakhtiniana, tomada como interação social, uma Sequência Didática, seguindo os moldes de Schneuwly, Noverraz e Dolz (2004) e de Lopes-Rossi (2011), foi elaborada para o gênero discursivo cordel. 
A apresentação da situação, vista sob a ótica da obra dos autores da escola de Genebra, elegeu as duas dimensões necessárias ao surgimento da elaboração da sequência: a apresentação do problema e o planejamento dos conteúdos. No caso da proposta feita para o gênero cordel, a dimensão do problema centrou-se na dificuldade dos alunos na escrita de cordéis, sendo essa escrita necessária à participação deles num concurso de cordel; e a dimensão dos conteúdos, relacionada à estrutura do gênero a ser produzido. Essa situação inicial, portanto, serviu para orientar os alunos sobre o que foi estudado. Nessa direção, os alunos tomaram consciência de que a SD partiu de uma situação que se apresentou como um problema de comunicação e que, para resolvê-lo, foi necessário conhecer os conteúdos abordados. Segundo Schneuwly, Noverraz e Dolz (2004, p. 85), "as sequências didáticas devem ser realizadas no âmbito de um projeto de classe, elaborado durante a apresentação da situação, pois este torna as atividades de aprendizagem significativas e pertinentes", o que nos fez compreender que toda a elaboração deveria partir de uma situação real de interação do gênero com o seu contexto de uso, exatamente como ocorreu. Ademais, o professor deve observar, quando da elaboração da SD, qual o gênero a ser abordado, quem o produzirá, a quem ele será dirigido e qual o suporte no qual se materializará. Nesse contexto, a escolha do gênero foi feita principalmente porque os alunos poderiam participar efetivamente de um concurso de literatura de cordel como autores de textos inéditos produzidos no âmbito da sala de aula, o que nos reportou à nossa questão de pesquisa abordada na introdução deste trabalho.

Desse modo, a relevância da proposta recaiu sobre uma situação comunicativa real viabilizando o trabalho com a escrita como prática social que convidou os alunos à interação por meio da autoria de textos de cordéis autênticos. Quanto às expectativas de aprendizagem para a SD planejada, estas foram bastante pertinentes em virtude do resgate, feito para as aulas de língua portuguesa, de um trabalho com um gênero considerado marginal, isto é, que não figura na listagem canônica da literatura brasileira, talvez pela constante proximidade com a oralidade. No entanto, o fato de se propor um trabalho com um gênero como esse fez com que as aulas fossem ressignificadas, uma vez que a proposta apontou para o aprofundamento dos conhecimentos culturais de um gênero que há muito é preterido pela escola em favor da literatura considerada canônica.

A principal tarefa a ser desenvolvida com o gênero escolhido foi a de trabalhar os seus aspectos temáticos, composicionais e estilísticos (BAKHTIN, 2003), proporcionando aos alunos conhecimentos suficientes para a elaboração de textos autorais a fim de que pudessem concorrer a um concurso de literatura de cordel promovido pela Associação Cultural Casa do Cordel de Natal/RN. Contudo, outras nuanças metodológicas geraram expectativas de aprendizagens que foram perseguidas, como a exploração de questões linguísticas e estruturais dos textos produzidos e o sucesso ou o insucesso da Sequência Didática elaborada, refletindo o fazer do professor. No que diz respeito ao instrumento utilizado como pressupostos da geração de dados da pesquisa, foi aplicado um questionário com os alunos, embasado em Marinho e Pinheiro (2012), sendo parte da Sequência Didática composta por três módulos: um de leitura, outro de escrita e um terceiro de divulgação. A elaboração dessa sequência gerou a produção de um Caderno Didático sobre o gênero discursivo cordel. 
Cada módulo foi elaborado com a intenção de fazer com que os alunos desenvolvessem habilidades e competências que os tornassem sujeitos da interação.

Assim, por meio dos módulos trabalhados, os alunos puderam ler o gênero, produzi-lo e divulgá-lo com propriedade. Para acompanhar o processo de ensino-aprendizagem para uma Sequência Didática nos moldes propostos, é importante que o professor esteja atento ao modo como todas as etapas serão avaliadas. Sendo assim, a avaliação deve ser feita de maneira contínua, dando oportunidade aos alunos, e ao próprio professor, de perceberem o que foi alcançado, com base nos objetivos pretendidos; e de redefinirem ações com base nos propósitos ainda não atingidos. 0 processo avaliativo, por esse viés, ganha a condição de continuidade por não ter condicionantes fechadas. Para o nosso trabalho, não houve aplicação de testes a fim de verificar quantitativamente a aprendizagem, mas uma autoavaliação que pôde ser feita colaborativamente entre professor e alunos após a aplicação de cada módulo. Contudo, ao final do Módulo de Divulgação, é importante que seja proposta a aplicação de um instrumento de avaliação que poderá ajudar o professor a compreender como os alunos se apropriaram do gênero em estudo.

O Quadro 1, a seguir, mostra as etapas planejadas para o cumprimento do Módulo de Leitura.

Quadro 1 - Descrição das etapas da SD para o Módulo de Leitura

\begin{tabular}{|c|c|c|c|c|c|}
\hline \multicolumn{6}{|c|}{ MÓDULO LEITURA } \\
\hline Etapas & $\begin{array}{l}\text { Procedimentos } \\
\text { Metodológicos }\end{array}$ & Objetivos & Duração & $\begin{array}{c}\text { Materiais } \\
\text { Necessários }\end{array}$ & Avaliação \\
\hline 1a etapa & $\begin{array}{l}\text { Ativação dos } \\
\text { conhecimentos } \\
\text { prévios sobre o } \\
\text { cordel }\end{array}$ & $\begin{array}{l}\text { Motivar os alunos } \\
\text { para a leitura do gê- } \\
\text { nero e para a ativi- } \\
\text { dade a ser realizada }\end{array}$ & $30 \mathrm{~min}$ & $\begin{array}{l}\text { Quadro branco, caneta para } \\
\text { quadro, cadernos, exempla- } \\
\text { res de folhetos de cordel }\end{array}$ & Contínua \\
\hline $2^{\mathrm{a}}$ etapa & $\begin{array}{l}\text { Leitura de } \\
\text { cordéis }\end{array}$ & $\begin{array}{l}\text { Desenvolver o gos- } \\
\text { to pelo gênero cor- } \\
\text { del por meio da } \\
\text { leitura }\end{array}$ & $30 \mathrm{~min}$ & $\begin{array}{l}\text { Folhetos de cordéis } \\
\text { Variados }\end{array}$ & Contínua \\
\hline $3^{\underline{a}}$ etapa & $\begin{array}{l}\text { Trabalho com a } \\
\text { estrutura do } \\
\text { cordel }\end{array}$ & $\begin{array}{l}\text { Reconhecer a es- } \\
\text { trutura do gênero } \\
\text { cordel: rima, estro- } \\
\text { fe e ritmo }\end{array}$ & $\begin{array}{l}\text { Duas } \\
\text { aulas de } \\
50 \mathrm{~min}\end{array}$ & $\begin{array}{l}\text { Folhetos de cordéis } \\
\text { variados, cordão, corte de } \\
\text { tecido, pegadores de rou- } \\
\text { pa, computador, projetor } \\
\text { multimídia, caixa de som, } \\
\text { folheto de cordel, caderno } \\
\text { dos alunos, quadro branco e } \\
\text { caneta para quadro branco }\end{array}$ & Contínua \\
\hline
\end{tabular}




\begin{tabular}{|c|c|c|c|c|c|}
\hline $4^{\mathrm{a}}$ etapa & $\begin{array}{l}\text { Varal de } \\
\text { folhetos para o } \\
\text { trabalho com a } \\
\text { temática }\end{array}$ & $\begin{array}{l}\text { Diferenciar o gêne- } \\
\text { ro cordel de outros } \\
\text { gêneros narrativos }\end{array}$ & $\begin{array}{l}\text { Duas } \\
\text { aulas de } \\
50 \mathrm{~min} .\end{array}$ & $\begin{array}{l}\text { Folhetos de cordéis } \\
\text { variados, cordão, corte de } \\
\text { tecido, pegadores de rou- } \\
\text { pa, computador, projetor } \\
\text { multimídia, caixa de som, } \\
\text { folheto de cordel, caderno } \\
\text { dos alunos, quadro branco e } \\
\text { caneta para quadro branco }\end{array}$ & Contínua \\
\hline $5 \underline{a}$ etapa & $\begin{array}{l}\text { Trabalhando a } \\
\text { audição }\end{array}$ & $\begin{array}{l}\text { Diferenciar a varia- } \\
\text { ção rítmica dos ver- } \\
\text { sos do cordel. }\end{array}$ & $\begin{array}{l}\text { Duas } \\
\text { aulas de } \\
50 \mathrm{~min}\end{array}$ & $\begin{array}{l}\text { Computador, caixa de som, } \\
\text { projetor multimídias, folhe- } \\
\text { tos de cordel, caderno, qua- } \\
\text { dro branco e caneta para } \\
\text { quadro branco }\end{array}$ & Contínua \\
\hline $6^{\underline{a}}$ etapa & $\begin{array}{c}\text { Leitura } \\
\text { compartilhada }\end{array}$ & $\begin{array}{l}\text { Desenvolver o gos- } \\
\text { to pela leitura dos } \\
\text { cordéis de modo } \\
\text { compartilhado }\end{array}$ & $\begin{array}{c}\text { Duas } \\
\text { aulas de } \\
50 \mathrm{~min}\end{array}$ & $\begin{array}{l}\text { Computador, projetor } \\
\text { multimídia, folhetos de cor- } \\
\text { del impressos e digitaliza- } \\
\text { dos, caderno dos alunos, } \\
\text { quadro branco e caneta } \\
\text { para quadro branco, } \\
\text { xilogravuras, cartolinas, } \\
\text { canetas hidrográficas, cola } \\
\text { e fita adesiva }\end{array}$ & Contínua \\
\hline 7므 etapa & $\begin{array}{c}\text { Compreensão } \\
\text { textual }\end{array}$ & $\begin{array}{l}\text { Desenvolver o sen- } \\
\text { so de compreensão } \\
\text { das histórias de } \\
\text { cordel lidas }\end{array}$ & $\begin{array}{c}\text { Duas } \\
\text { aulas de } \\
50 \mathrm{~min}\end{array}$ & $\begin{array}{l}\text { Texto de cordel impresso, } \\
\text { computador com internet, } \\
\text { projetor multimídia, caixa } \\
\text { de som, quadro branco e } \\
\text { caneta para quadro }\end{array}$ & Contínua \\
\hline
\end{tabular}

Fonte: autoria própria (2016)

O Módulo de Leitura foi pensado para ser desenvolvido em sete etapas, tendo como tempo estimado para esse fim um total de dez aulas de 50 minutos. Esse módulo foi considerado primordial no desenvolvimento da sequência, pois foi por meio dele que se realizou uma parte considerável das ações destinadas à motivação para a escrita. Nesse processo, os alunos precisam ser envolvidos no desenvolvimento da proposta e o Módulo de Leitura é a porta de entrada para um trabalho bem-sucedido. Esse era o momento em que os alunos, provavelmente, entrariam em contato pela primeira vez 
com o gênero discursivo pré-selecionado. Por essa razão, o planejamento das ações precisava ser bem delineado.

Para Lopes-Rossi (2011), o Módulo de Leitura permite ao aluno a discussão, o comentário e o conhecimento das condições de circulação do gênero selecionado para o desenvolvimento da prática por meio de vários exemplos. Para tanto, foram selecionados vários textos de autores cordelistas para que os alunos pudessem (re) conhecer o gênero, direcionando o olhar, especialmente para a estrutura textual: ritmo e rima. Foi nesse Módulo de Leitura, também, que os alunos, por meio da amostragem de textos de cordéis selecionados, puderam diferenciar esse gênero de outros da ordem do narrar. Além disso, outros objetivos puderam ser alcançados nesse módulo, como a compreensão do gênero por meio do contato visual com os folhetos (suporte) e a identificação das várias temáticas abordadas. Nesse sentido, a leitura contribuiu para a compreensão do gênero em estudo, porque foi dada ao aluno a oportunidade de se apropriar das suas características por meio de diversos exemplos de textos. Para esse módulo, a seleção de textos de cordel ultrapassou a quantidade de vinte exemplares. Outra questão relevante de cada módulo são os materiais necessários para o desdobramento da SD. Para o Módulo de Leitura, especificamente, foram pensados os seguintes materiais: computador com acesso à internet, projetor multimídia, caixa de som, folhetos de cordel, vídeos com audições sobre o gênero cordel, caderno dos alunos para anotações importantes sobre o gênero em abordagem, quadro branco e caneta para quadro branco, entre outros.

Conforme o Quadro 2, as etapas do Módulo de Leitura são sete, conforme apresen- tadas a seguir. A $1^{\text {a }}$ etapa intitulada Acorda cordel: uma palavra de motivação foi pensada para motivar os alunos para a leitura dos folhetos de cordel e para a pesquisa a ser realizada. A $2^{a}$ etapa, Acordando o cordel: a leitura em ação, teve como objetivo desenvolver o gosto pelo cordel por meio da leitura de um cordel em voz alta. A $3^{a}$ etapa, Acordando o cordel: pelejando com a estrutura, teve como objetivo reconhecer a estrutura do texto de cordel por meio da leitura de mais um texto. Desse modo, os alunos contemplaram, além dos aspectos discursivos, as variantes da estrutura: métrica, rima e ritmo.

A 4 ${ }^{\mathrm{a}}$ etapa, Acordando o cordel: um varal de folhetos, promoveu a leitura de diversos folhetos de cordel, com o foco direcionado ao cordel 0 romance do pavão misterioso, de José Camelo de Melo Rezende (SILVA, 2008). Foi uma etapa que permitiu aos alunos a diferenciação do gênero cordel de outros gêneros discursivos, proporcionando ainda mais o gosto pela leitura dos textos dessa natureza. A 5 ${ }^{\underline{a}}$ etapa, Acordando o cordel: apurando a audição, teve como um dos objetivos diferenciar a variação rítmica que os cordéis podem proporcionar e, por essa razão, a audição de vários cordéis foi proposta nessa etapa. A 6 ${ }^{\underline{a}}$ etapa, dividida em três fases, teve como título: Acordando o cordel: (com)partilhando a leitura. Esse foi o momento no qual os alunos participaram de atividades como a leitura compartilhada, a montagem de texto de cordel e o relacionamento da leitura com as xilogravuras dos folhetos. A 7aㅡ etapa, Acordando o cordel: compreendendo a história, foi a última a ser abordada com a intenção de fazer com que os alunos pudessem praticar uma atividade de interpretação de um dos cordéis de Leandro Gomes de Barros, considerado o maior cordelista de todos os tempos. 
Descreveremos, no Quadro 2, a seguir, Módulo de Escrita. Esse módulo foi pensado as etapas necessárias para a composição do para ser desenvolvido em nove etapas.

Quadro 2 - Descrição das etapas do Módulo de Escrita

\begin{tabular}{|c|c|c|c|c|c|}
\hline \multicolumn{6}{|c|}{ MÓDULO ESCRITA } \\
\hline Etapas & $\begin{array}{l}\text { Procedimentos } \\
\text { Metodológicos }\end{array}$ & Objetivos & Duração & $\begin{array}{c}\text { Materiais } \\
\text { Necessários }\end{array}$ & Avaliação \\
\hline $\begin{array}{c}1^{\underline{a}} \\
\text { etapa }\end{array}$ & $\begin{array}{c}1^{\underline{a} \text { fase - }} \\
\text { conversando sobre } \\
\text { a escrita } \\
2^{\underline{a} \text { fase - }} \\
\text { Apresentação de } \\
\text { slides } \\
3^{\underline{a} \text { fase - }} \\
\text { Atividades de produ- } \\
\text { ção escrita } \\
4^{\underline{a} \text { fase - }} \\
\text { escrita com a função } \\
\text { prazerosa }\end{array}$ & $\begin{array}{l}\text { Compreender a } \\
\text { importância da } \\
\text { escrita }\end{array}$ & $\begin{array}{l}\text { Duas } \\
\text { aulas de } \\
50 \mathrm{~min}\end{array}$ & $\begin{array}{l}\text { Computador com internet, } \\
\text { projetor } \\
\text { multimídia, atividade } \\
\text { impressa, } \\
\text { textos de cordel, caderno } \\
\text { dos alunos, quadro branco } \\
\text { e caneta para quadro } \\
\text { branco. }\end{array}$ & contínua \\
\hline $\begin{array}{c}2^{\underline{a}} \\
\text { etapa }\end{array}$ & 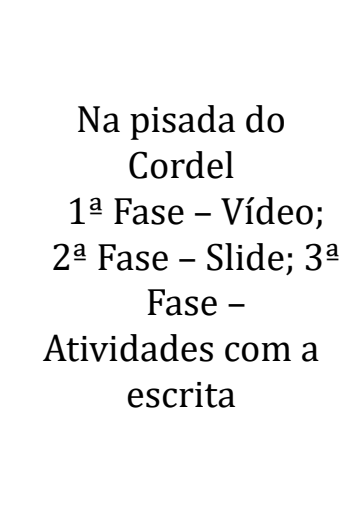 & $\begin{array}{l}\text { Compreender a } \\
\text { importância do } \\
\text { cordel }\end{array}$ & $\begin{array}{l}\text { Duas } \\
\text { aulas de } \\
50 \mathrm{~min}\end{array}$ & $\begin{array}{l}\text { Computador } \\
\text { com acesso à internet, pro- } \\
\text { jetor multimídia, caixa de } \\
\text { som, slides sobre o cordel, } \\
\text { cordéis } \\
\text { impressos, texto de cordel } \\
\text { impresso, } \\
\text { caderno dos alunos para } \\
\text { atividades } \\
\text { escritas, quadro branco e } \\
\text { caneta para quadro branco. }\end{array}$ & contínua \\
\hline $\begin{array}{c}3^{\underline{a}} \\
\text { etapa }\end{array}$ & Na batida da métrica & $\begin{array}{l}\text { Compreender } \\
\text { a metrificação } \\
\text { do verso na } \\
\text { composição da } \\
\text { sextilha }\end{array}$ & $\begin{array}{l}\text { Duas } \\
\text { aulas de } \\
50 \mathrm{~min}\end{array}$ & $\begin{array}{l}\text { Material impresso (ativi- } \\
\text { dade) } \\
\text { caderno dos alunos, quadro } \\
\text { branco e caneta para qua- } \\
\text { dro branco }\end{array}$ & contínua \\
\hline $\begin{array}{c}4^{\underline{a}} \\
\text { etapa }\end{array}$ & $\begin{array}{l}\text { Variação } \\
\text { linguística: o } \\
\text { uso da } \\
\text { linguagem } \\
\text { regional }\end{array}$ & $\begin{array}{l}\text { Observar o } \\
\text { uso da } \\
\text { linguagem } \\
\text { regional na } \\
\text { escrita dos } \\
\text { folhetos de } \\
\text { cordel }\end{array}$ & $\begin{array}{l}\text { Duas } \\
\text { aulas de } \\
50 \mathrm{~min}\end{array}$ & $\begin{array}{l}\text { Computador com acesso à } \\
\text { internet, projetor multimí- } \\
\text { dia, caixa de som, texto de } \\
\text { cordel impresso, } \\
\text { caderno dos alunos para } \\
\text { atividade escrita, quadro } \\
\text { branco e caneta para qua- } \\
\text { dro branco. }\end{array}$ & Contínua \\
\hline
\end{tabular}




\begin{tabular}{|c|c|c|c|c|c|}
\hline $\begin{array}{c}5^{\underline{a}} \\
\text { etapa }\end{array}$ & $\begin{array}{l}\text { Escrevendo com } \\
\text { expressividade: mar- } \\
\text { cas de autoria } \\
\text { 1a fase - escrita co- } \\
\text { letiva com a partici- } \\
\text { pação do professor } \\
2^{\text {a }} \text { fase - escrita em } \\
\text { grupo com a partici- } \\
\text { pação do professor } \\
3^{\text {a fase - reescrita, }} \\
\text { um momento para } \\
\text { repensar o texto. }\end{array}$ & $\begin{array}{l}\text { Produzir } \\
\text { cordéis a partir } \\
\text { das temáticas } \\
\text { sugeridas }\end{array}$ & $\begin{array}{l}\text { quatro } \\
\text { aulas de } \\
50 \mathrm{~min}\end{array}$ & $\begin{array}{l}\text { Computador, projetor } \\
\text { multimídia, caderno dos } \\
\text { alunos, quadro branco e } \\
\text { caneta para quadro } \\
\text { branco. }\end{array}$ & Contínua \\
\hline $\begin{array}{c}6^{\mathbf{a}} \\
\text { etapa }\end{array}$ & $\begin{array}{c}\text { Aula de campo: } \\
\text { visitação à Casa do } \\
\text { Cordel }\end{array}$ & $\begin{array}{l}\text { Conhecer a } \\
\text { Casa do Cordel } \\
\text { em Natal/RN e } \\
\text { sua } \\
\text { importância } \\
\text { como } \\
\text { patrimônio da } \\
\text { cultura local }\end{array}$ & $\begin{array}{l}\text { Três } \\
\text { horas }\end{array}$ & $\begin{array}{l}\text { Ônibus para transportar } \\
\text { os alunos, caderno dos } \\
\text { alunos para anotações, } \\
\text { texto impresso sobre a } \\
\text { história da Casa do Cordel, } \\
\text { autorização dos pais para } \\
\text { que os alunos possam } \\
\text { visitar a instituição. }\end{array}$ & Contínua \\
\hline $\begin{array}{c}7^{\mathrm{a}} \\
\text { etapa }\end{array}$ & $\begin{array}{c}\text { Oficina com } \\
\text { cordelista local }\end{array}$ & $\begin{array}{l}\text { Interagir com } \\
\text { um autor } \\
\text { cordelista para } \\
\text { compreender } \\
\text { como se dá } \\
\text { o processo } \\
\text { de criação de } \\
\text { cordéis } \\
\end{array}$ & $\begin{array}{l}\text { Duas } \\
\text { horas e } \\
\text { trinta } \\
\text { minutos }\end{array}$ & $\begin{array}{l}\text { Computador, projetor } \\
\text { multimídia, caderno dos } \\
\text { alunos, material do } \\
\text { cordelista, quadro branco e } \\
\text { caneta para quadro branco. }\end{array}$ & contínua \\
\hline $\begin{array}{c}8^{\mathbf{a}} \\
\text { etapa }\end{array}$ & $\begin{array}{c}\text { Oficina com } \\
\text { xilógrafo local }\end{array}$ & $\begin{array}{l}\text { Interagir com } \\
\text { um autor } \\
\text { xilógrafo para } \\
\text { compreender } \\
\text { melhor como } \\
\text { se dá o } \\
\text { processo de } \\
\text { criação das } \\
\text { xilogravuras }\end{array}$ & $\begin{array}{l}\text { Duas } \\
\text { horas e } \\
\text { trinta } \\
\text { minutos }\end{array}$ & $\begin{array}{l}\text { Computador } \\
\text { com acesso à internet, } \\
\text { projetor multimídia, } \\
\text { folhas em branco para } \\
\text { criação dos desenhos, lápis } \\
\text { grafite, borracha, quadro } \\
\text { branco e caneta para } \\
\text { quadro branco, material } \\
\text { do xilógrafo convidado. }\end{array}$ & contínua \\
\hline $\begin{array}{c}9^{9} \underline{a} \\
\text { etapa }\end{array}$ & $\begin{array}{c}\text { Primeira experiên- } \\
\text { cia com a escrita do } \\
\text { cordel }\end{array}$ & $\begin{array}{l}\text { Escrever um } \\
\text { cordel para } \\
\text { participar de } \\
\text { um concurso } \\
\text { de literatura de } \\
\text { cordel }\end{array}$ & $\begin{array}{l}\text { Seis } \\
\text { aulas de } \\
50 \mathrm{~min}\end{array}$ & $\begin{array}{l}\text { Computador } \\
\text { com acesso à internet, } \\
\text { projetor multimídia, } \\
\text { folhas em branco para } \\
\text { criação dos desenhos, lápis } \\
\text { grafite, borracha, quadro } \\
\text { branco e caneta para } \\
\text { quadro branco, materiais } \\
\text { do concurso de cordel e } \\
\text { ficha de inscrição }\end{array}$ & contínua \\
\hline
\end{tabular}

Fonte: autoria própria (2016) 
Algumas das etapas constituintes desse módulo foram mais longas, pois exigiram um tempo maior para ser concluídas e foram divididas em fases. Outras foram trabalhadas no período de aula normal. Os conteúdos explorados nesse módulo estiveram relacionados, basicamente, ao estudo da estrutura do cordel: a métrica, a estrofe, o verso, a rima, o ritmo, mas também foram trabalhados as temáticas, os poetas cordelistas, os repentistas, os desenhos das capas dos cordéis, as xilogravuras e os xilógrafos. Num primeiro momento, a proposta do Módulo de Escrita foi desenvolvida como um trabalho coletivo. Como sugere Lopes-Rossi (2004), o desenvolvimento da escrita pode e deve ser feito coletivamente. Por essa razão, as primeiras produções com o gênero foram feitas com a participação de todos. Uma das produções foi construída pelo grande grupo e a outra, em grupos menores. As duas atividades foram mediadas pelo professor. O Módulo de Escrita, o maior de todos, foi desenvolvido, aproximadamente, em 24 aulas de 50 minutos, tempo esse somado a 8 horas para a aplicação das oficinas de cordel e de xilogravura (com cordelista e xilógrafo locais) e para a aula de campo (visitação à Associação Cultural Casa do Cordel).

De um modo geral, os materiais necessários para o desenvolvimento do Módulo de Escrita foram os seguintes: computador com acesso à internet, projetor multimídia, caixa de som, folhetos de cordel impressos e digitalizados, vídeos sobre o gênero discursivo cordel, slides sobre a temática, caderno dos alunos para anotações, atividades com exercícios impressos, quadro branco e caneta para quadro branco. 0 Quadro 2 sintetiza as etapas realizadas no decorrer desse módulo. Tais etapas compõem um cabedal de estratégias elaboradas para dar conta da produção escrita dos alunos. Nessa perspectiva, a abordagem dessas etapas está alinhada à teoria bakhtiniana que concebe a produção de um gênero discursivo com um propósito concreto. 0 fato de os alunos produzirem seus próprios textos, levando em consideração todos os aspectos estruturais do gênero, permitiu o acompanhamento do processo de autoria da escrita deles. Essa não foi uma tarefa fácil de ser conseguida, pois a estrutura da escrita do cordel requer bastantes cuidados, como, por exemplo, com as rimas, com a métrica, com a composição das sextilhas, com o ritmo, além de atenção às questões que envolvem a temática. Após a primeira atividade de escrita, o trabalho foi voltado para o processo de reescrita dos textos produzidos. Nessa direção, uma das opções adotadas no trabalho com a reescrita, além do "recado ao escrevente" abordado na seção escrita, foi a da "correção participativa” proposta pro Lopes-Rossi (2004, p. 77). Desse modo, cada aluno contou com a intervenção dos demais colegas nos textos produzidos individualmente, tendo ainda a mediação do professor. Essa foi uma tarefa extremamente importante para colocar em prática as atividades previstas para esse módulo. A 1a etapa, intitulada Escrita, para que te quero? foi desenvolvida em quatro fases e teve como objetivo principal destacar a importância do objeto escrita e de suas várias funções nas atividades comunicativas no cotidiano das pessoas, entre elas, a de provocar prazer. A $2^{\mathrm{a}}$ etapa, na Pisada do cordel, visava ressaltar a importância da escrita dos cordéis e foi desenvolvida em três fases, sendo a última delas direcionada para a execução de uma atividade escrita com as rimas de um cordel pré-selecionado. A 3 a etapa, Na batida da métrica, levou em conta o trabalho com uma atividade elaborada especialmente para a compreensão dos alu- 
nos para a métrica dos versos. A $4^{\mathrm{a}}$ etapa, Variação linguística: o uso da linguagem regional, voltou-se para uma discussão em torno da variação linguística utilizada nos cordéis. A 5a etapa, Escrevendo com expressividade: a constituição das marcas de autoria, foi desenvolvida em três fases e teve como foco a escrita e a reescrita dos primeiros textos de cordéis produzidos coletivamente. A 6 ${ }^{\mathrm{a}}$ etapa, Aula de campo: visitação à Casa do Cordel, implicou na visitação à Casa do Cordel para que os alunos pudessem ter contato com cordelistas locais. A 7a etapa, Oficina com cordelista local José Acaci, foi desenvolvida na própria escola com uma oficina de cordel aplicada por um cordelista local. A 8 a etapa, Oficina com xilógrafo local Erick Lima, também foi desenvolvida na própria escola, com um xilógrafo local, que ensinou aos alunos a técnica da xilogravura. A 9a etapa e última etapa, A escrita com propósito social, culminou na produção dos cordéis para a participação no concurso de literatura de cordel promovido pela Associação Cultural Casa do Cordel.

O terceiro e último módulo da Sequência Didática elaborada para a aplicação das atividades planificadas com o gênero discursivo cordel foi o de divulgação. 0 Quadro 3, a seguir, mostra as duas etapas de trabalho para a execução do módulo de divulgação. A primeira destinada à Mostra de Cordel, quando os alunos apresentaram os folhetos produzidos à comunidade escolar; e a segunda voltada para a participação dos alunos no evento de divulgação do concurso para o qual houve a produção dos textos autorais.

Quadro 3 - Etapas da SD para o Módulo de Divulgação

\begin{tabular}{|c|c|c|c|c|c|}
\hline \multicolumn{6}{|c|}{ MÓDULO DE DIVULGAÇÃO } \\
\hline Etapas & $\begin{array}{l}\text { Procedimentos } \\
\text { Metodológicos }\end{array}$ & Objetivos & Duração & $\begin{array}{c}\text { Materiais } \\
\text { Necessários }\end{array}$ & Avaliação \\
\hline $\begin{array}{c}1 \underline{\mathrm{a}} \\
\text { etapa }\end{array}$ & $\begin{array}{l}1^{\mathrm{a}} \text { mostra de } \\
\text { cordel }\end{array}$ & $\begin{array}{l}\text { Apresentar à } \\
\text { comunidade } \\
\text { escolar os cordéis } \\
\text { produzidos durante o } \\
\text { desenvolvimento do } \\
\text { projeto }\end{array}$ & $\begin{array}{l}\text { Doze } \\
\text { horas }\end{array}$ & $\begin{array}{l}\text { Computador com } \\
\text { internet, projetor } \\
\text { multimídia, caixa } \\
\text { de som, cordéis } \\
\text { impressos, materiais } \\
\text { para composição da } \\
\text { sala temática: corte de } \\
\text { tecido (chita), cordão } \\
\text { de pegadores de roupa, } \\
\text { peças do cenário } \\
\text { sertanejo }\end{array}$ & contínua \\
\hline $\begin{array}{c}2^{\underline{a}} \\
\text { etapa }\end{array}$ & $\begin{array}{l}\text { Premiação do } \\
\text { Concurso 1ํo } \\
\text { Concurso de } \\
\text { Cordel da Casa } \\
\text { do Cordel }\end{array}$ & $\begin{array}{l}\text { Participar de } \\
\text { solenidade de } \\
\text { premiação do } 1^{o} \\
\text { Concurso de } \\
\text { Cordel da Casa do } \\
\text { Cordel }\end{array}$ & $\begin{array}{l}\text { Duas } \\
\text { horas }\end{array}$ & $\begin{array}{l}\text { Ônibus para transportar } \\
\text { os alunos até o local do } \\
\text { evento. }\end{array}$ & contínua \\
\hline
\end{tabular}

Fonte: autoria própria (2016). 
O planejamento para esse módulo levou em conta o gênero discursivo cordel, os meios de divulgação desse gênero, os momentos de interação gerados a partir de sua aplicação, a divulgação além da escola, a Mostra de Cordel que foi realizada na escola e o resultado na participação do concurso. Pensando no fato de que muitos leitores teriam acesso ao trabalho dos alunos, o cuidado que tivemos com esse módulo foi redobrado, em função de uma apresentação de qualidade do material produzido. Por isso, fizemos uma revisão criteriosa em todos os materiais (textos, xilogravuras) antes da impressão em gráfica. Importante destacar que nesse processo de criação os alunos têm a possibilidade de compreender a escrita como processo constituído de várias etapas.

Os objetivos pretendidos para esse módulo estão situados, entre outros, na divulgação dos cordéis produzidos pelos alunos em atividades de linguagens dentro e fora do espaço escolar; na participação dos alunos na Mostra do Cordel que foi promovida no ambiente escolar; e na vivência dos momentos de divulgação dos concursos para os quais os cordéis foram produzidos.

Em relação ao tempo estimado para a realização do módulo em questão, foi de 18 horas aproximadamente. Já os materiais utilizados foram: computador com acesso à internet, projetor multimídia, caixa de som, folhetos de cordéis impressos, diversos materiais cenográficos para composição da sala temática (pedaço de tecido - chita - cordões, pegadores de roupa, peças de cenário que remetessem à vivência do homem do sertão).

Esse módulo, portanto, foi planejado para dar uma noção de conclusibilidade à pesquisa, levando em consideração a concepção bakhtiniana, visto que o trabalho com esse gênero não ficou totalmente aca- bado. Entretanto, para divulgar a produção feita pelos alunos, algumas ações foram pensadas observando a "forma típica de circulação do gênero" (LOPES-ROSSI, 2004, p. 78). Considerar os folhetos de cordel produzidos pelos alunos, nesse sentido, foi fundamental para essa etapa, fazendo-os chegar a vários leitores, tanto os do entorno escolar como os de fora dele.

\section{Considerações finais}

Compreendemos que todos os objetivos pretendidos inicialmente foram atingidos. Por meio da planificação da SD, conseguimos desenvolver a competência leitora e escritora nos alunos do 9o ano, reconhecendo que o cordel é um gênero discursivo que tem sua importância no meio social como elemento cultural carregado de valor, mesmo sendo considerado por muitos como um gênero menor e não fazendo parte do cânone literário escolar. Diante dos resultados que obtivemos, faz-se necessário dizer que foi imprescindível subsidiar o nosso trabalho no aporte teórico que adotamos durante toda a nossa pesquisa. As escolhas que fizemos teoricamente, como nos lembra Antunes (2009, p. 39), são essenciais para construirmos o conhecimento, porque tudo depende de um "conjunto de princípios teóricos". Essa sustentação teórica foi fundamental para desenvolvermos todas as ações previstas na pesquisa em função da aquisição de habilidades e competências relacionadas à leitura e à escrita dos alunos por meio do gênero em questão. Mas, sobretudo, a base teórica com a qual dialogamos serviu para fazer com que refletíssemos sobre a nossa prática docente, o que nos dá a certeza de que todo o trabalho desenvolvido foi de grande valia.

Se considerarmos o trabalho no que diz respeito às práticas de leitura, podemos 
concluir que a competência leitora dos alunos foi ampliada com sucesso, especialmente no que se refere ao gênero com o qual trabalhamos, visto que não circula comumente na esfera escolar. Entretanto, consideramos que os ganhos foram muito maiores em relação à competência escrita dos alunos. Se atentarmos para a produção autoral deles, observamos que conseguiram se apropriar da estrutura composicional de um gênero discursivo como o cordel, que não é fácil de ser escrito, impregnando nos textos um estilo próprio capaz de vencer um concurso de literatura. Ademais, pudemos observar que a relação dos alunos com o gênero discursivo cordel serviu para compreendermos que a linguagem é uma atividade interativa e constitutiva do homem que vai construindo os enunciados para se comunicar nas várias esferas de atividades humanas pelas quais circula, utilizando-se, para isso, dos gêneros do discurso (BAKHTIN, 2003). Assim sendo, ancorados na perspectiva do pensamento bakhtiniano, podemos dizer que os alunos se apropriaram, por meio da leitura, de um gênero com o qual mal tinham contato para se posicionar discursivamente com mais liberdade por meio da escrita.

\section{Referências}

ANTUNES, I. Aula de Português - encontro e interações. São Paulo: Parábola, 2003.

BAKHTIN, M. Estética da Criação Verbal. 4. ed. Tradução de Paulo Bezerra. São Paulo: Martins Fontes, 2003.

DOLZ, J.; NOVERRAZ, M.; SCHNEUWLY, B. Sequências didáticas para o oral e a escrita: apresentação de um procedimento. In: SCHNEUWLY, B.; DOLZ, J. Gêneros orais e escritos na escola. Tradução de Roxane Rojo e Glaís Sales Cordeiro. Campinas: Mercado das Letras, 2004.

FREIRE, P. Pedagogia da autonomia: saberes necessários à prática educativa. São Paulo: Paz e Terra, 2006.

LOPES-ROSSI, M. A. G. Gêneros discursivos no ensino de leitura e produção de textos. In.: KARWOSKY, A. M.; GAYDECZKA, B.; BRITO, K. S. (Org.). Gêneros Textuais: reflexões e ensino. São Paulo: Parábola, 2011.

MARINHO, A. C.; PINHEIRO, H. 0 cordel no cotidiano escolar. São Paulo: Cortez, 2012. (Coleção Trabalhando com... na escola).

SILVA, G. F. (Org.). 100 histórias de cordéis segundo a Academia Brasileira de Literatura de Cordel. Mossoró: Queima Bucha, 2008.

Recebido em: 18/03/2021 Aprovado em: 10/07/2021 